
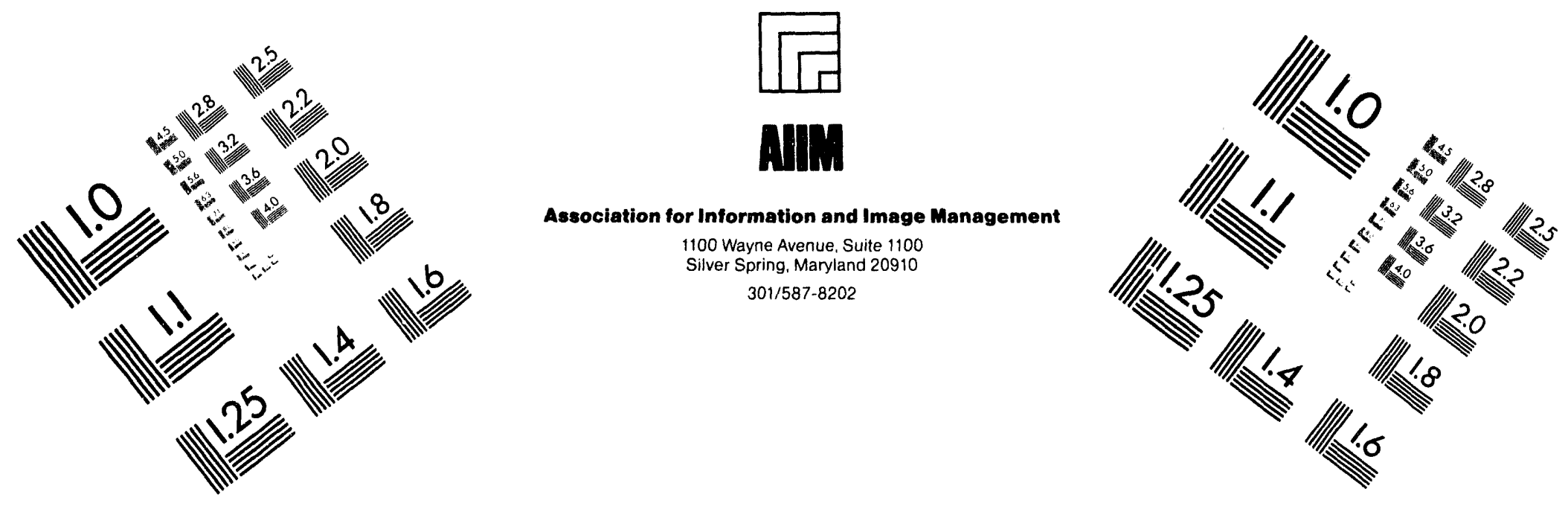

Centimeter

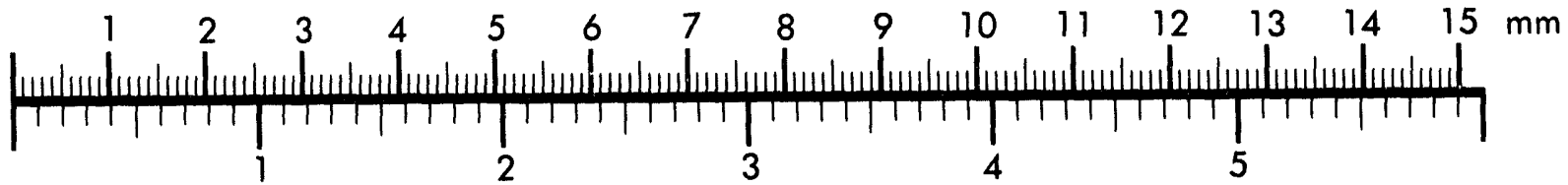
Inches
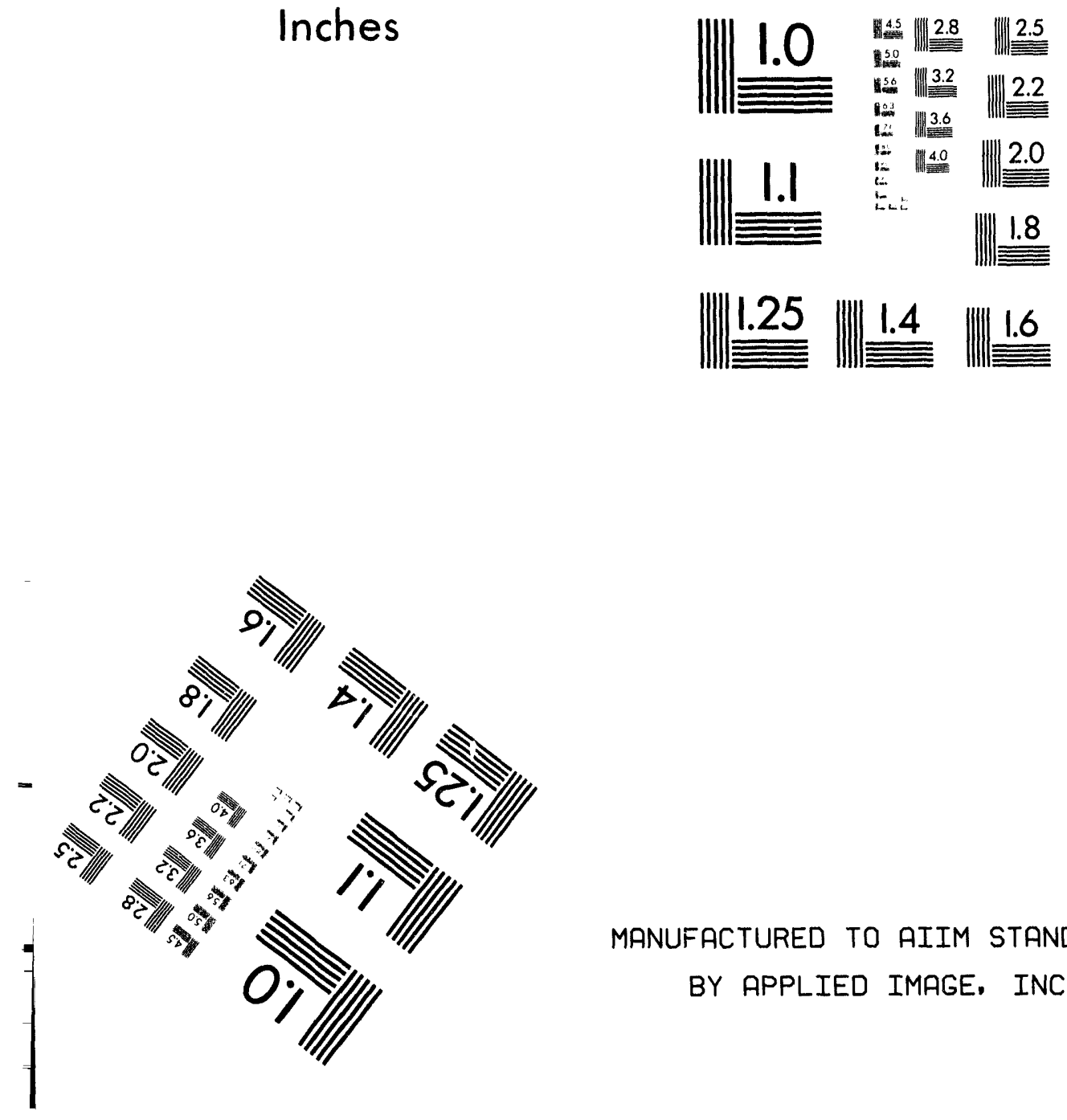

MANUFACTURED TO AIIM STANDARDS

BY APPLIED IMAGE, INC.

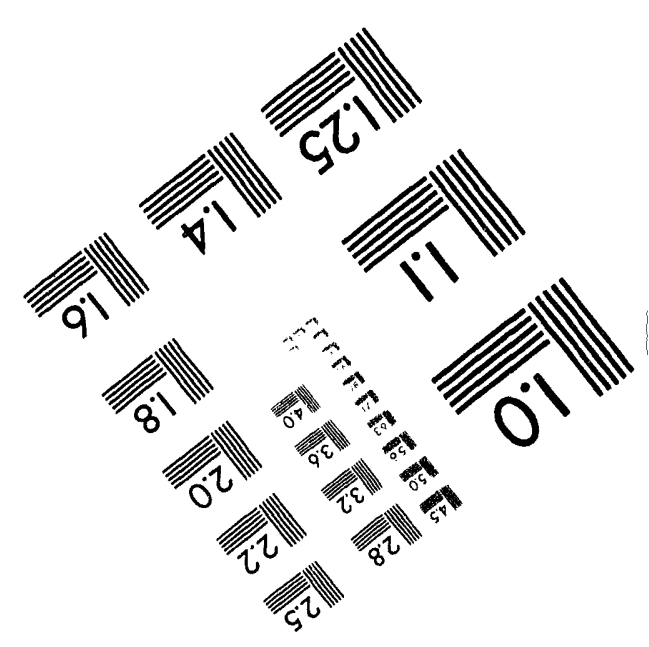



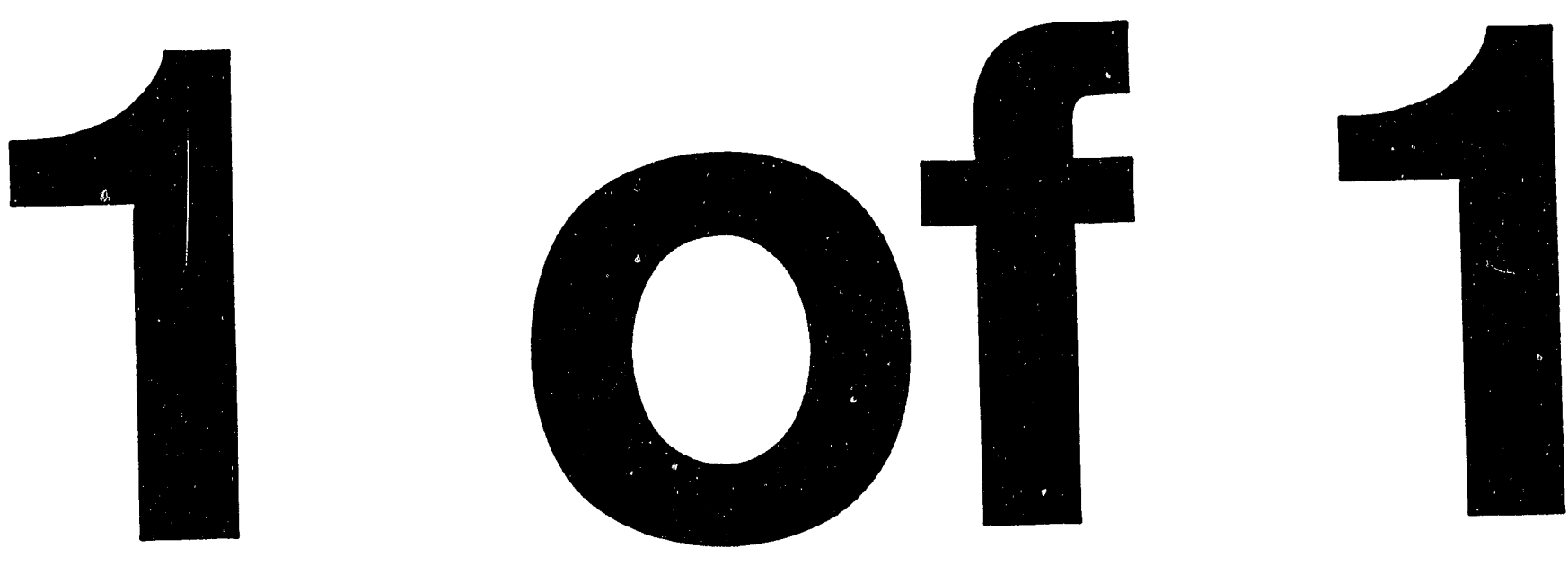


\title{
Measurements of Line Overlap for Resonant Spoiling of X-ray Lasing Transitions
}

\author{
P. Beiersdorfer \\ S. R. Elliott \\ B. J. MacGowan \\ J. Nilsen
}

This paper was prepared for submittal to the
Proceedings of the 4th International Colloquium on X-ray Lasers
Williamsburg, VA
May 16-20, 1994

June 1994
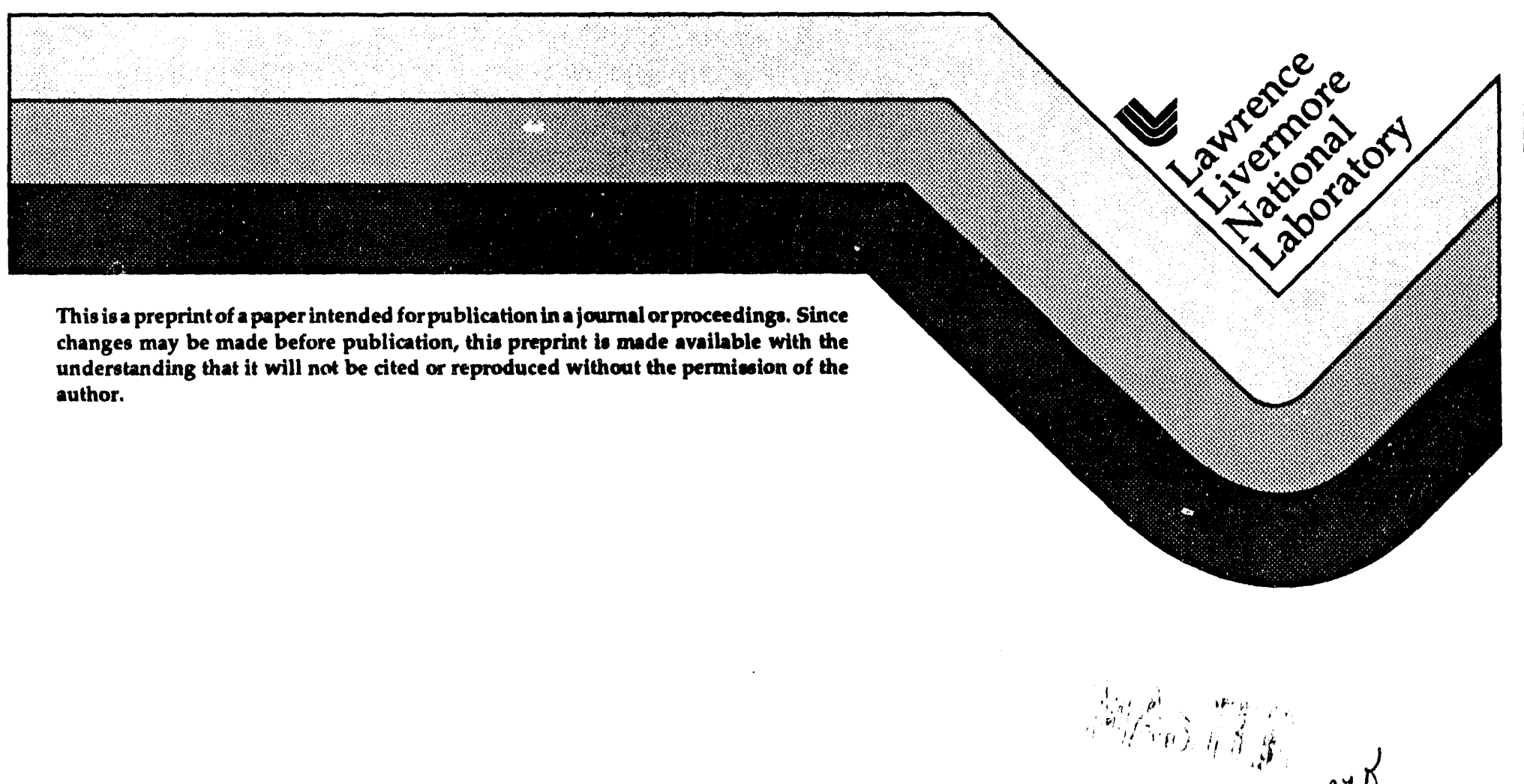


\section{DISCLAIMER}

This document was prepared as an account of work sponsored by an agency of the United States Government. Neither the United States Govemment nor the University of California nor any of their employees, makes any warranty, express or implied, or assumes any legal liability or responsibility for the accuracy, completeness, or usefulness of any information, apparatus, produch, or process disclosed, or represents that its use would not infringe privately owned rights. Reference herein to any specific commercial products, process, or service by trade name, trademark, manufacturer, or otherwise, does not necessarily constitute or imply its endorsement, recommendation, or favoring by the United States Government or the University of Califomia. The views and opinions of authors expressed herein do not necessarily state or reflect those of the United States Govemment or the University of Califomia, and shall not be used for advertising or product endorsement purposes. 


\title{
Measurements of Line Overlap for Resonant Spoiling of X-ray Lasing Transitions
}

\author{
P. Beiersdorfer, S. R. Elliott, B. J. MacGowan, and J. Nilsen
}

Lawrence Livermore National Laboratory, Livermore, CA 94551

\begin{abstract}
High-precision measurements are presented of candidate line pairs for resonant spoiling of $x$-ray lasing transitions in the nickellike $\mathrm{W}^{46+}$, the neonlike $\mathrm{Fe}^{16+}$, and the neonlike $\mathrm{La}^{47+} \mathrm{x}$-ray lasers. Our measurements were carried out with high-resolution crystal spectrometers, and a typical precision of $20-50 \mathrm{ppm}$ was achieved. While most resonances appear insufficient for effective photo-spoiling, two resonance pairs are identified that provide a good overlap. These are the $4 p_{1 / 2} \rightarrow 3 d_{3 / 2}$ transition in nickellike $W^{46+}$ with the $2 \mathrm{p}_{3 / 2} \rightarrow 1 \mathrm{~s}_{1 / 2}$ transition in hydrogenic $\mathrm{Al}^{12+}$, and the $3 s_{1 / 2} \rightarrow 2 \mathrm{p}_{3 / 2}$ transition in neonlike $\mathrm{La}^{47+}$ with the $1^{1} \mathrm{~S}_{0}-2^{1} \mathrm{P}_{1}$ line in heliumlike $\mathrm{Ti}^{20+}$.
\end{abstract}

\section{Introduction}

Modification of the x-ray laser kinetics by resonant photo-pumping is of practical and scientific interest. For example, resonant photo-pumping has been proposed as an efficient way to achieve lasing [1]. Conversely, resonant photo-pumping may be used to spoil lasing. This allows tailoring of the laser to yield monochromatic output that suits available $\mathrm{x}$-ray optics. It can also be used to probe the laser kinetics in order to obtain a better understanding of the principles of $x$-ray lasing.

Photo-pumping requires resonances on the order of a few hundred parts per million $(\mathrm{ppm})$. Candidate resonances must be experimentally verified, as the accuracy achieved by calculations is typically only within a range of a few parts per thousand for the multi-electron ions of interest in x-ray lasing. In the following we present measurements of candidate resonances for spoiling of $\mathrm{x}$-ray laser transitions. The lasers considered are the nickellike $\mathrm{W}^{46+}$ laser shown to lase at $43.1 \AA$. [2] and the neonlike $\mathrm{Fe}^{16+}$ laser shown to lase at $254.9,347.6$, and $388.9 \AA$ [3]. We also investigated spoiling of a proposed neonlike $\mathrm{La}^{47+}$ laser, which might lase at 57,3 and $128 \AA$ [4]. Lasing in $\mathrm{La}^{47+}$ cannot yet be attained with existing facilities, but might be achieved in experiments with the planned National Ignition Facility.

\section{Spoiling of the Nickellike $W^{46}+$ Laser}

A diagram showing the levels involved in the resonant spoiling of the nickellike $\mathrm{W}^{46+}$ laser is shown in Fig. 1 . The $43-\AA$ lasing transition proceeds from level $\left(3 \mathrm{~d}_{3 / 2}, 4 \mathrm{~d}_{3 / 2}\right)_{\mathrm{J}=0}$ to level $\left(3 \mathrm{~d}_{3 / 2}, 4 \mathrm{p}_{1 / 2}\right)_{\mathrm{J}=1}$. Raising the population of the lower level will diminish or destroy the population inversion necessary for lasing and thus will 
spoil the $43-\AA$ laser. This is accomplished by pumping with an appropriate line whose wavelength is nearly coincident with that of the dump transition from level $\left(3 d_{3 / 2}, 4 p_{1 / 2}\right)_{j=1}$ to the ${ }^{1} S_{0}$ ground level. The energy of the $4 p_{1 / 2} \rightarrow 3 d_{3 / 2}$ dump line was predicted to be $1728 \mathrm{eV}$, or $7.150 \AA$ [5]. A candidate pump line is provided by the $2 \mathrm{p}_{3 / 2} \rightarrow 1 \mathrm{~s}_{1 / 2}$ Ly- $\alpha_{1}$ line in hydrogenic $\mathrm{Al}^{12+}$ at $7.1709 \AA[6]$, as shown in Fig. 1. Other candidate pump lines are the $2 \mathrm{p}_{1 / 2} \rightarrow 1 \mathrm{~s}_{1 / 2} \mathrm{Ly}-\alpha_{2}$ line in $\mathrm{Al}^{12+}$ (predicted at $7.1763 \AA[6])$, the transition from $\left(2 \mathrm{p}_{1 / 2}, 3 \mathrm{~d}_{3 / 2}\right)_{\mathrm{J}=1}$ to the ${ }^{1} \mathrm{~S}_{0}$ ground level in neonlike $\mathrm{Br}^{25+}$ (predicted at $\left.7.1700 \AA[7]\right)$, and the transition from $\left(3 \mathrm{~d}_{3 / 2}, 4 \mathrm{f}_{5 / 2}\right)_{\mathrm{J}=1}$ to the ${ }^{1} \mathrm{~S} 0$ ground level in nickellike Erot (predicted at $7.1760 \AA[8]$ ).

FIGURE 1. Energy level diagram showing the mechanism for spoiling of the $43-\AA$ nickellike $W^{46+}$ laser by resonant photo-pumping with hydrogenlike $\mathrm{Al}^{\mathrm{P}+}$. Increasing the population of the $4 p$ level spoils a possible inversion and thus lasing between the $4 p$ and $4 d$ levels.
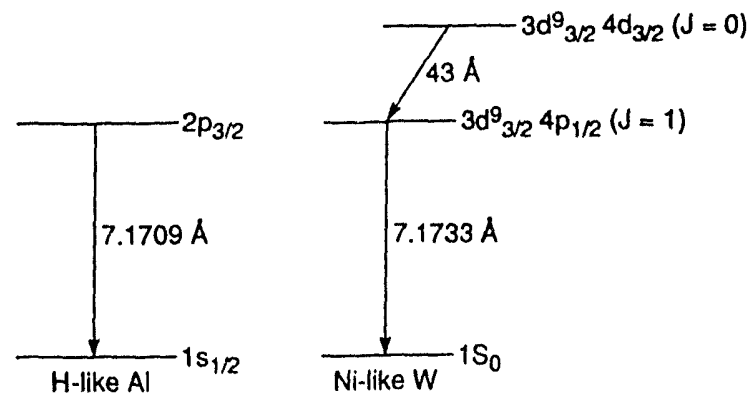

The candidate photo-pumping resonances are verified in measurements on the Livermore electron beam ion trap (EBIT). The device uses a monoenergetic electron beam to produce and excite a particular ion species of interest, and a given line can be observed free of blends with collisional or dielectronic satellites [9]. Recording spectra with the evacuated flat-crystal spectrometer described in Ref. [10], and using the Lyman- $\alpha$ lines of $\mathrm{Al}^{12+}$ as reference lines, we find $7.1733 \pm 0.0003 \AA$ for the tungsten line. Moreover, we measured $7.1837 \pm 0.0020$ $\AA$ for the wavelength of the $4 \mathrm{f}_{5 / 2} \rightarrow 3 \mathrm{~d}_{3 / 2}$ transition in nickellike $\mathrm{Er}^{40+}$ and $7.1685 \pm 0.0002 \AA$ for that of the $3 \mathrm{~d}_{3 / 2} \rightarrow 2 \mathrm{p}_{1 / 2}$ transition in neonlike $\mathrm{Br}^{25+}$. A summary of the results is given in Table $I$.

Table I. Comparison of measured and predicted wavelengths of candidate photo resonances in the $\mathrm{Ni}$-like $\mathrm{W}^{46+}$ and $\mathrm{Ne}$-like $\mathrm{Fe}^{16+}$ and $\mathrm{La}^{47+}$ lasers (in $\mathrm{A}$ ). Lines used as reference standards are denoted by (*).

\begin{tabular}{|c|c|c|c|c|}
\hline Laser & Upper Level & lon & Theory & Experiment \\
\hline $\begin{array}{l}\mathrm{Fe}^{16+} \\
\mathrm{La}^{47+}\end{array}$ & 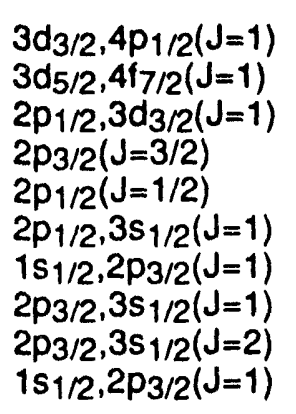 & $\begin{array}{l}\mathrm{W}^{46+} \\
\mathrm{Er}^{40+} \\
\mathrm{Br}^{25+} \\
\mathrm{Al}^{12+} \\
\mathrm{Al}^{12+} \\
\mathrm{Fe}^{16+} \\
\mathrm{F}^{7+} \\
\mathrm{La}^{47+} \\
\mathrm{La}^{47+} \\
\mathrm{Ti}^{20+}\end{array}$ & $\begin{array}{c}7.150 \text { [Ref.5] } \\
7.1760 \text { [Ref.8] } \\
7.1700 \text { [Ref.7] } \\
7.17091 \text { [Ref.6] } \\
7.17632 \text { [Ref.6] } \\
16.797 \text { [Ref.7] } \\
16.8064 \text { [Ref.11] } \\
2.61001 \text { [Ref.13] } \\
2.61330 \text { [Ref.13] } \\
2.61040 \text { [Ref.11] }\end{array}$ & $\begin{array}{c}7.1733(3) \\
7.1830(20) \\
7.1685(2) \\
7.17091\left(^{*}\right) \\
7.17632\left(^{*}\right) \\
16.772(3) \\
16.8064\left(^{*}\right) \\
2.61015(10) \\
2.61330(5) \\
2.61040\left(^{*}\right)\end{array}$ \\
\hline
\end{tabular}


The measured location of the candidate pump lines relative to the measured position of the $4 p_{1 / 2} \rightarrow 3 d_{3} / 2$ dump transition in tungsten is shown schematically in Fig. 2. The best resonance is found with the $2 \mathrm{p}_{3 / 2} \rightarrow 1 \mathrm{~s}_{1 / 2} \mathrm{Ly}-\alpha_{1}$ line in hydrogenic All $2+$. The two lines differ by $2.4 \pm 0.3 \mathrm{~m} \AA$ or $335 \mathrm{ppm}$. Figure 2 also gives a schematic overview of the predicted locations of the various lines. A comparison of the predicted and measured locations illustrates the unequivocal need for precise measurements of candidate resonances.

Figure 2. Comparison of predicted and measured location of the $3 d-4 p$ transition in nickel-like $W^{46+}$ and of various candidate resonant photo-pumping transitions.
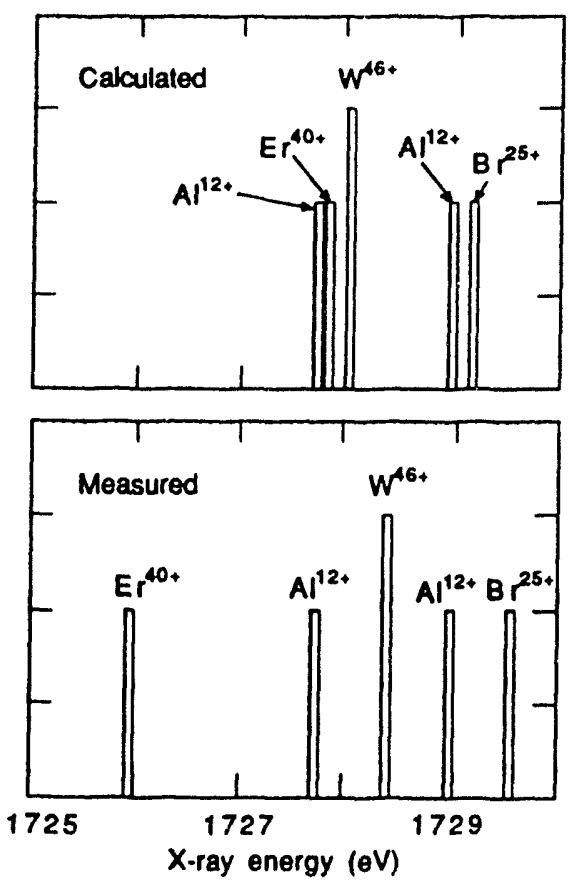

\section{Spoiling of the Neonlike Fe ${ }^{16}+$ Laser}

A diagram showing the levels involved in the resonant spoiling of the neonlike $\mathrm{Fe}^{16+}$ laser is shown in Fig. 3. Resonant photo-pumping of the $2 \mathrm{p}_{1 / 2}-3 \mathrm{~s}_{1 / 2}$ transition in neonlike iron at $16.772 \AA$ enhances the population of the $\left(2 \mathrm{p}_{1 / 2}, 3 \mathrm{~s}_{1 / 2}\right)_{\mathrm{J}=1}$ level, which is the lower level for several $3 \mathrm{p} \rightarrow 3 \mathrm{~s}$ lasing transitions, including the $255-\AA$ lasing line observed to dominate lasing in neonlike iron [3]. A candidate pump line is given by the $1^{1} S_{0}-2^{1} P_{1}$ line in heliumlike $F^{7+}$.

The candidate photo-pumping resonance is again verified in measurements on the EBIT facility. Using the wavelengths of the ${ }^{1} \mathrm{~S}_{0}-2^{1} \mathrm{P}_{1}$ and ${ }^{1} \mathrm{~S}_{0}-2^{3} \mathrm{~S}_{1}$ lines calculated by Drake [11], (16.8064 and $17.1528 \AA$, respectively) to calibrate the measurements, we find $16.772 \pm 0.003 \AA$ for the $2 \mathrm{p}_{1 / 2}-3 \mathrm{~s}_{1 / 2}$ line in neonlike iron $\mathrm{Fe}^{16+}$. The separation between it and the heliumlike $\mathrm{F}^{7+}$ resonance line is $35 \pm 3$ $\mathrm{mA}$, or $2,000 \mathrm{ppm}$. 
Figure 3. Energy level diagram showing the mechanism for spoiling of lasing in neonlike $\mathrm{Fe}^{16+}$ by resonant photo-pumping of the $2 p_{1 / 2}-3 s_{1 / 2}$ transition by the $1^{1} S_{0}-2^{1} p_{1}$ transition in heliumlike $F^{7+}$. Increasing the population of the 3s level spoils a possible inversion and thus lasing between the $3 s$ and $3 p$ levels.

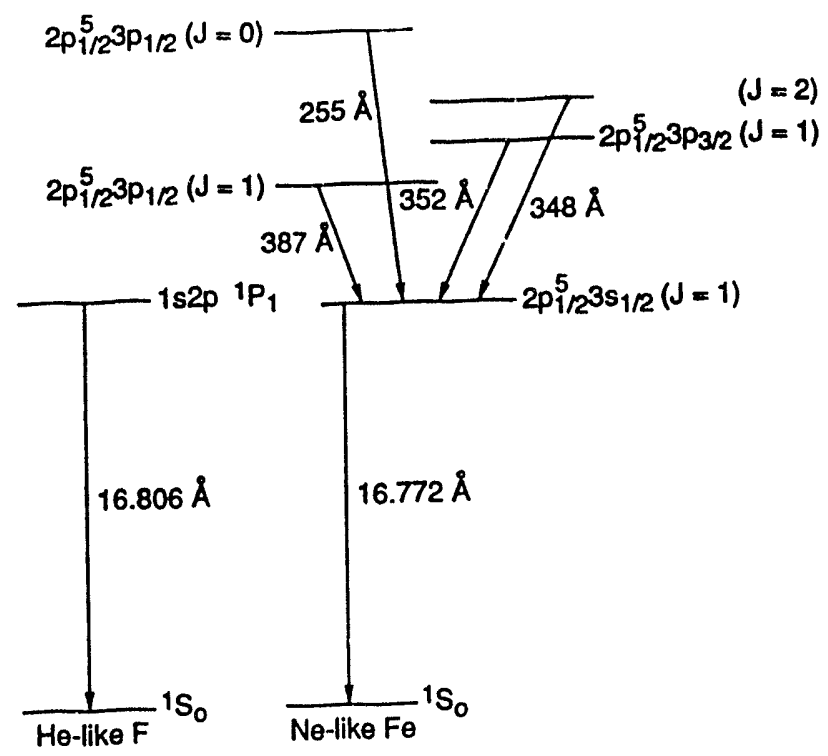

\section{Spoiling of the Neonlike $\mathrm{La}^{47+}$ Laser}

The highest $-\mathrm{Z}$ neonlike laser demonstrated so far is neonlike $\mathrm{Ag}^{37+}$ with lasing lines at $100 \AA$ [12]. This experiment was carried out on the NOVA laser facility and appears to represent the upper limit of $Z$ that can be made to lase with existing facilities. As a result, a neonlike $\mathrm{La}^{47+}$ laser has not yet been demonstrated. Such a laser would, however, be feasible with the planned National Ignition Faciliy. If successful, lasing between the levels $\left(2 \mathrm{p}_{1} / 2,3 \mathrm{p}_{3} / 2\right)_{\mathrm{J}}=2$ and $\left(2 \mathrm{p}_{1 / 2}, 3 \mathrm{~s}_{1} / 2\right) \mathrm{J}=1$ and between the levels $\left(2 \mathrm{p}_{3} / 2,3 \mathrm{p}_{1} / 2\right) \mathrm{J}=2$ and $\left(2 \mathrm{p}_{3} / 2,3 \mathrm{~s}_{1} / 2\right) \mathrm{J}=1$ would result in lines at $58.3 \pm 2$ and $128.2 \pm 0.8 \AA$, as inferred from high-resolution measurements of the $2 \mathrm{p}-3 \mathrm{p}$ and $2 \mathrm{p}-3 \mathrm{~s}$ transitions [4]. Lasing would also be expected at $57 \AA$ between the levels $\left(2 \mathrm{p}_{3} / 2,3 \mathrm{p}_{3} / 2\right) \mathrm{J}=2$ and $\left(2 \mathrm{p}_{3} / 2,3 \mathrm{~s}_{1} / 2\right) \mathrm{J}=1$ as well as between other levels.

Resonant photo-pumping of the $2 \mathrm{p}_{3} / 2-3 \mathrm{~s}_{1 / 2}$ transition with the $1 \mathrm{~s} 2 \mathrm{p}{ }^{1} \mathrm{P}_{1} \rightarrow 1 \mathrm{~s}^{2}{ }^{1} \mathrm{~S}_{0}$ transition in heliumlike $\mathrm{Ti}^{20}+$ could be used to spoil lasing transitions involving the $\left(2 \mathrm{p}_{3 / 2}, 3 \mathrm{~s}_{1} / 2\right)_{\mathrm{J}=1}$ dump level. Drake [11] predicted the wavelength of the ${ }^{1} \mathrm{~S}_{0}-2^{1} \mathrm{P}_{1}$ line in heliumlike Ti20+ to be $2.6104 \AA$, while Ivanova and Gulov [13] predicted the wavelength of the transition from $\left(2 \mathrm{p}_{3} / 2,3 \mathrm{~s}_{1 / 2}\right) \mathrm{J}=1$ to the ${ }^{1} \mathrm{~S}_{0}$ ground level in neonlike $\mathrm{La}^{47+}$ to be $2.6100 \AA$.

The candidate photo-pumping resonance is verified in measurements on the Princeton Large Torus (PLT) tokamak using a Johann-type Bragg-crystal spectrometer [14]. Using $2.61040 \AA$ for the $1^{1} \mathrm{~S}_{0-2}{ }^{1} \mathrm{P}_{1}$ line in titanium to calibrate the spectrum, we find $2.61015 \pm 0.00010 \AA$ for the wavelength of the transition from $\left(2 \mathrm{p}_{3} / 2,3 \mathrm{~s}_{1 / 2}\right)_{\mathrm{J}=1}$ to the ${ }^{1} \mathrm{~S}_{0}$ ground level in neonlike lathanum $\mathrm{La}^{47+}$. We find $2.61330 \pm 0.00005 \AA$ for the neighboring transition from the $\left(2 \mathrm{p}_{3} / 2,3 \mathrm{~s}_{1 / 2}\right) \mathrm{J}=2$ level to ground. 


\section{Discussion}

Among the candidate resonances investigated only two are found that are sufficiently good to allow photo-pumping. The first is the resonance between the $2 \mathrm{p}_{3 / 2} \rightarrow 1 \mathrm{~s}_{1 / 2} \mathrm{Ly}-\alpha_{1}$ line in hydrogenic Al $1^{12+}$ and the $4 \mathrm{p}_{1 / 2} \rightarrow 3 \mathrm{~d}_{3 / 2}$ transition in nickellike $\mathrm{W}^{46+}$. The two lines differ by $335 \mathrm{ppm}$, which approximately equals the Doppler broadening of the aluminum line in a $500-\mathrm{eV}$ plasma. Moreover, the tungsten line differs only $420 \mathrm{ppm}$ from the $2 \mathrm{p}_{1 / 2} \rightarrow 1 \mathrm{~s}_{1 / 2} \mathrm{Ly}-\alpha_{2}$ line in hydrogenic $\mathrm{Al}^{12+}$, and the Ly- $\alpha_{2}$ line may also contribute to pumping the nickel-like transition, especially as the two Ly- $\alpha$ components blend into a sinigle line in optically thick plasmas. The fact that the tungsten line lies between the Ly- $\alpha$ lines is especially important in cases where plasma motion shifts the wavelength of the tungsten line (or that of the aluminum lines). Such a shift would improve the resonance, regardless of the relative direction of the motion.

The second, good resonance is found between the $3 \mathrm{~s}_{1} / 2 \rightarrow 2 \mathrm{p}_{3 / 2}$ line in neonlike lathanum $\mathrm{La}^{47+}$ and the $2 \mathrm{p}_{3 / 2} \rightarrow 1 \mathrm{~s}_{1 / 2}$ line in heliumlike $\mathrm{Ti}^{20+}$. The two lines differ by only $96 \mathrm{ppm}$, representing an excellent resonance for photo-pumping provided a neonlike lathanum $\mathrm{La}^{47+}$ laser were achieved with the National Ignition Facility or a similar laser facility with the more intensity and energy than currently available.

This work was performed under the auspices of the U.S. Department of Energy by Lawrence Livermore National Laboratory under contract No. W-7405-ENG-48.

\section{References}

1. A. V. Vinogradov, I. I. Sobelman, and E. A. Yukov, Sov. J. Quantum Electron. 59, 5 (1975); B. A. Norton and N. J. Peacock, J. Phys. B 8, 989 (1975); R. C. Elton, X-ray Lasers, (Academic Press, San Diego, 1990), pp. 99 - 198; C. H. Skinner, Phys. Fluids B 3, 2420 (1991).

2. B. J. MacGowan, et al., Phys. Rev. Lett. 65, 420 (1990).

3. J. Nilsen, J. C. Moreno, B. J. MacGowan, and J. A. Koch, Appl. Phys. B 57, 309 (1993).

4. P. Beiersdorfer, et al., Phys. Rev. A 37, 4153 (1988).

5. S. Maxon, et al., Rev. Lett. 63, 236 (1989).

6. W. R. Johnson and G. Soff, At. Data Nucl. Data Tables 33, 405 (1985).

7. J. A. Cordogan and S. Lunell, Phys. Scr. 33406 (1986).

8. J. Nilsen, Phys. Rev. A 40, 5440 (1989).

9. P. Beiersdorfer, et al., in $U V$ and $X$-ray Spectroscopy of Laboratory and Astrophysical Plasmas, ed. by E. Silver and S. Kahn (Cambridge University Press, Cambridge, 1993), p. 59.

10. P. Beiersdorfer and B. J. Wargelin, Rev. Sci. Instrum. 65, 13 (1994).

11. G. W. F. Drake, Can. J. Phys. 66, 586 (1988).

12. D. J. Fields, et al., Phys. Rev. A 46, 1606 (1992).

13. E. P. Ivanova and A. V. Gulov, At. Data Nucl. Data Tables 49, 1 (1991).

14. P. Beiersdorfer, Ph. D. thesis, Princeton University (1988). 

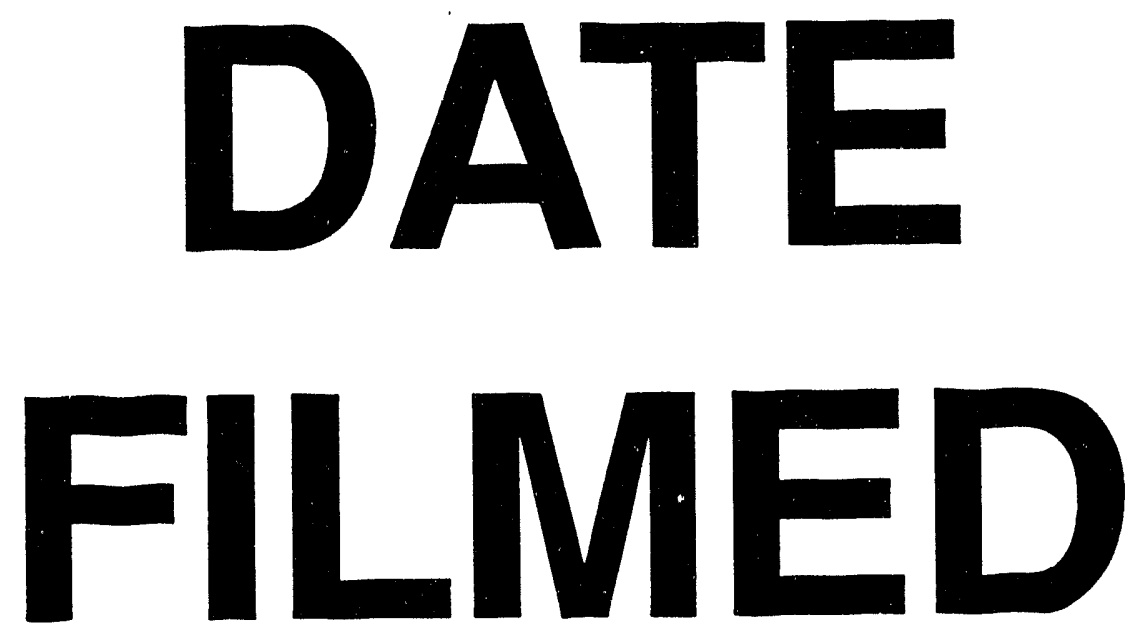

$9 / 29 / 94$
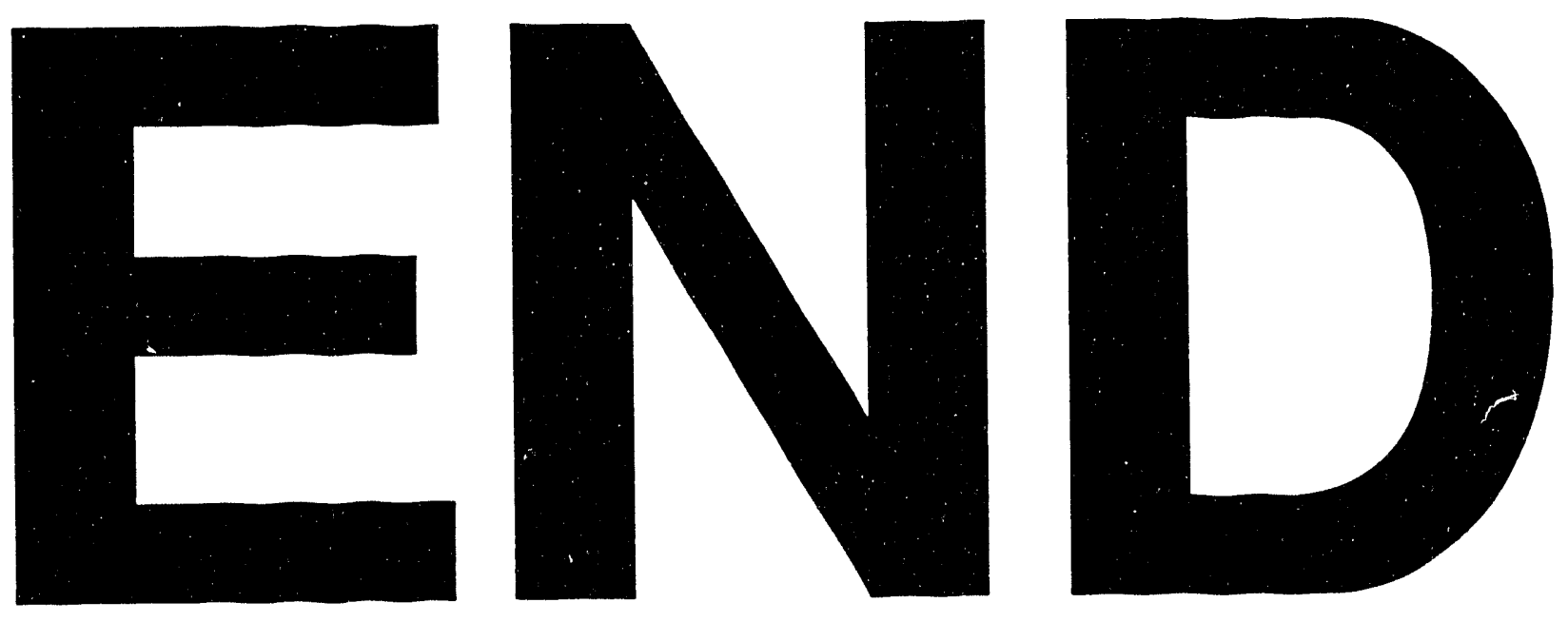


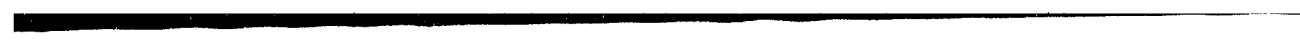

|

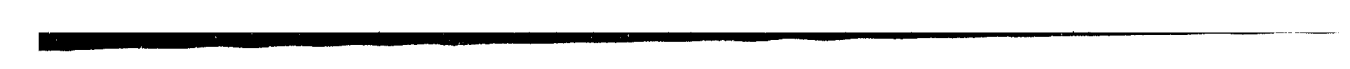

